\title{
EFICACIA JURÍDICA DE LA \\ NORMATIVA COMÚN EN PROCESOS DE INTEGRACIÓN REGIONAL, ESPECIAL REFERENCIA AL DERECHO DEL MERCOSUR
}

\section{EFICÁCIA JURÍDICA DAS NORMAS COMUNS EM PROCESSOS DE INTEGRAÇÃO REGIONAL, COM ESPECIAL REFERENCIA AO DIREITO DO MERCOSUL}

Daniel Pavón Piscitello

Resumen: El objetivo del presente artículo consiste en reflexionar sobre la eficacia jurídica de la normativa del MERCOSUR, concretamente en plantear la factibilidad de la aplicación de fundamentos y desarrollos de la doctrina jurisprudencial de la eficacia jurídica del derecho de integración de la Unión Europea al derecho de integración del MERCOSUR, principalmente a su derecho derivado, en orden a mejorar su efectividad y a contribuir desde el derecho al avance del proceso de integración, esencialmente ante situaciones o supuestos de incumplimiento estatal.

El artículo aborda la eficacia jurídica de la normativa común en el derecho de integración del MERCOSUR y sus posibilidades de desarrollo, a partir del propio ordenamiento jurídico del proceso de integración, estableciendo puntos comunes y divergentes con el derecho de integración de la Unión Europea, y proponiendo manifestaciones concretas de la aludida eficacia jurídica de las normas comunes, con un contenido y alcance ajustado al ámbito del MERCOSUR.

A partir del carácter obligatorio del derecho de integración para los Estados integrados y del rol de los particulares en tanto sujetos protagónicos del mismo, las conclusiones del artículo giran en torno a la factibilidad de potenciar y/o consagrar en el ámbito del derecho de integración derivado del MERCOSUR diversas manifestaciones de la eficacia jurídica de la normativa común frente a incumplimientos estatales, con la finalidad de lograr la adecuación de sus conductas a derecho y de resguardar los

* Universidad Católica de Córdoba, Argentina.

E-mail: danielpavonpiscitello@yahoo.es

Recibido: 10/02/2017. Aceptado: 14/03/2017. 
derechos de los particulares.

Resumo: O objetivo do presente artigo consiste em refletir sobre a eficácia jurídica das normas do MERCOSUL, concretamente em esboçar a viabilidade da aplicação de fundamentos e de desenvolvimentos da doutrina jurisprudencial da eficácia jurídica do direito de integração da União Europeia ao direito da integração do MERCOSUL, principalmente para o seu direito derivado, com o intuito de melhorar sua efetividade $e$ de contribuir, com base no direito, ao avanço do processo de integração, principalmente perante as situações ou os prenúncios de seu descumprimento por parte do Estado.

$O$ artigo trata da eficácia jurídica das normas comuns no direito de integração do MERCOSUL e suas possibilidades de desenvolvimento, a partir do próprio ordenamento jurídico do processo de integração, estabelecendo pontos comuns e divergentes com o direito da integração da União Europeia e sugerindo manifestações concretas da aludida eficácia jurídica das normas comuns, com um conteúdo e um alcance ajustado ao âmbito do MERCOSUL.

A partir do caráter obrigatório do direito de integração para os Estados integrados e do papel dos particulares enquanto sujeitos protagonistas do mesmo, as conclusões do artigo giram em torno da viabilidade de potencializar e/ou aplicar no âmbito do direito de integração derivado do MERCOSUL diversas manifestações da eficácia jurídica das normas comuns com a finalidade de aplicar corretivos frente aos descumprimentos estatais do disposto por elas, com o propósito de alcançar a adequação dos seus comportamentos ao direito e de preservar os direitos dos particulares.

Palabras clave: Derecho de integración, Eficacia normativa, MERCOSUR Palavras-chave: Direito da integração, Eficácia normativa, MERCOSUL

\section{INTRODUCCIÓN}

El objetivo del trabajo consiste en reflexionar sobre la eficacia jurídica de la normativa común en procesos de integración regional, específicamente en analizar la factibilidad de la aplicación de aspectos centrales de la doctrina jurisprudencial de la eficacia jurídica del derecho de integración de la Unión Europea, con énfasis en desarrollos vinculados a las directivas como fuente de su derecho derivado, al derecho de integración derivado del MERCOSUR, en orden a mejorar la aplicación efectiva de este último. La pretensión es poder contribuir al avance del proceso de integración del MERCOSUR, a partir de las posibilidades que ofrece el propio derecho de integración del bloque regional y su estructura institucional actual ${ }^{1}$, recurriendo a desarrollos

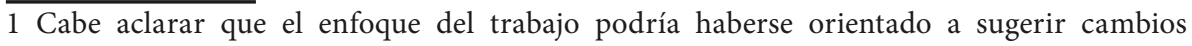


originados en el proceso de integración europeo que resultan susceptibles de ser tomados como referencia, siempre contemplando las semejanzas y las diferencias existentes entre los dos esquemas de integración ${ }^{2}$.

La pertinencia del planteamiento encuentra soporte dada la actual situación de parálisis que experimenta el proceso de integración del MERCOSUR, parálisis que pone en riesgo su futuro y derivada de un conjunto de factores, entre ellos y en lo que a efectos del presente trabajo interesa, la escasa aplicación efectiva de su derecho de integración derivado vinculante (Decisiones del Consejo del Mercado Común, Resoluciones del Grupo Mercado Común, directivas de la Comisión de Comercio del MERCOSUR), derecho de carácter obligatorio para los Estados Partes pero dependiente en la práctica de un procedimiento de vigencia simultánea que, como regla, requiere que las distintas normas comunes sean incorporadas por todos los Estados Partes a sus respectivos ordenamientos jurídicos internos o nacionales para recién, a partir de ese momento, ser aplicables en las distintas jurisdicciones ${ }^{3}$. Lo expresado implica que el incumplimiento de uno de los Estados Partes de su obligación de incorporar la normativa común propia del derecho de integración derivado del MERCOSUR, genera en los hechos una especie de efecto bloqueo que impide la aplicación de la misma no solamente en su jurisdicción, sino en el conjunto de los Estados Partes ${ }^{4}$.

profundos en la estructura institucional y en el sistema jurídico del proceso de integración del MERCOSUR, pero que se optó por trabajar a partir de la realidad actual del bloque regional, y de las posibilidades que ella ofrece desde la postura aquí sostenida.

2 Se entiende que el derecho de integración como categoría jurídica genérica brinda comunes denominadores que hacen factibles desarrollos, respuestas o soluciones jurídicas similares a partir de argumentos jurídicos coincidentes y de realidades próximas, siempre contemplando las necesarias adecuaciones, adaptaciones y matizaciones en función de las diferencias existentes entre los procesos de integración y sus sistemas jurídicos. Lo señalado ha sido reconocido por los tribunales arbitrales del MERCOSUR en diversos pronunciamientos en los que se recurrió a la jurisprudencia del Tribunal de Justicia de la Unión Europea estableciendo distintos niveles de aproximación y diferenciación entre los procesos de integración, pudiéndose destacar el Laudo TPR 01/2005, del 20 de diciembre de 2005, del que cabría deducir que, a nivel interpretativo, los tribunales primero deben recurrir al derecho del MERCOSUR, y posteriormente antes que al derecho internacional, al derecho de integración como categoría jurídica de carácter autónomo. Al respecto puede verse: PAVÓN, D.; SCHMIDT, J. "In the footsteps of the ECJ: First decision of the Permanent MERCOSUR-Tribunal". Kluwer Law International. 2007, vol 34, $\mathrm{n}^{\circ} 3$, p. 283 y ss.

3 En lo referente a este punto el contraste entre las reacciones del sistema jurídico de la Unión Europea y del sistema jurídico del MERCOSUR ante problemáticas próximas desde lo normativo y desde lo fáctico resulta notorio: frente al desarrollo e implementación de soluciones o respuestas jurídicas que posibilitaron la aplicación de la normativa común y el funcionamiento y avance del proceso de integración europeo, la parálisis del proceso de integración del MERCOSUR, parálisis en los hechos se traduce tanto a nivel de relaciones estatales como en la vida cotidiana de los habitantes del MERCOSUR (preeminencia de intereses y decisiones nacionales unilaterales, falta de resolución de conflictos interestatales, afectación a la libertad de circulación, trabas arancelarias y no arancelarias a la libre circulación de bienes, etc.).

4 A lo expresado se añade un problema práctico extra, vinculado a lo que se denomina vigencia asimétrica de la normativa común, que implica que en múltiples ocasiones los Estados Partes del MERCOSUR aplican a nivel interno estatal las normas comunes sin esperar el 
Frenteala situación expuesta, elúnicoresguardojurídicoactualmente posible en el marco del proceso de integración regional es la recurrencia de los demás Estados Partes al Sistema de Solución de Controversias del MERCOSUR con el objeto de que se declare la responsabilidad del Estado Parte incumplidor o de los Estados Partes incumplidores, aunque quedando privada la normativa común de operatividad y aplicabilidad para regular las relaciones jurídicas a la que está destinada hasta tanto todos los Estados Partes adecuen sus conductas a derecho y procedan a incorporar la misma, no pudiendo los particulares mientras ello no ocurra invocar eventuales derechos otorgados por normativa común, ni ante sus autoridades nacionales ni ante los órganos comunes del proceso de integración, y beneficiarse de ello.

En este contexto, si bien los órganos comunes del MERCOSUR han insistido en la importancia de la incorporación de las normas del derecho de integración derivado en los Estados Partes, y los tribunales arbitrales del bloque regional han reafirmado tanto el carácter obligatorio de la normativa común como el consecuente deber de incorporación de la misma, poco se ha avanzado en la aplicación de medidas prácticas que permitan contrarrestar el aludido efecto bloqueo ante incumplimientos estatales, lo que se traduce en una relación susceptible de sintetizarse en obligatoriedad - incumplimiento - no vigencia de la normativa común. Por otra parte, si bien una fracción de la doctrina especializada ha señalado la incongruencia de la situación expuesta, incluso proponiendo algunas medidas tendentes a mejorar la aplicabilidad del derecho de integración derivado del MERCOSUR, su influencia ha sido escasa frente a la dudosa voluntad de los Estados Partes por revertir la situación, en parte porque se hace depender estas medidas de lo dispuesto en los derechos nacionales de cada uno los Estados Partes -de la jerarquía normativa interna otorgada al derecho internacional-, en parte porque estas medidas proponen cambios radicales respecto al sistema de integración actual -entre otros, pasar de un sistema intergubernamental a un sistema supranacional-, no haciendo eje en las posibilidades que la realidad del actual sistema ofrece.

La cuestión planteada consiste entonces en reflexionar sobre el real alcance de la obligatoriedad de las normas comunes adoptadas en el seno de los órganos del bloque regional, esto es si las normas comunes obligatorias deben acatarse sin más por cada uno de los Estados Partes, o si estas normas comunes quedan sujetas a condición o a un proceso de validación ex post en cada una de las jurisdicciones estatales, condición o validación determinadas por la incorporación normativa,

cumplimiento del aludido procedimiento de vigencia simultánea, lo que provoca situaciones de falta de vigencia común pero de vigencia interna, las que poseen un efecto discriminador entre los particulares de los distintos Estados Partes en tanto sujetos del derecho común, a la vez que atenta contra la necesaria seguridad jurídica. 
incorporación que implica la recepción de las mismas, que les otorgaría validez y eficacia jurídica interna, y determinaría su posición dentro de las pirámides jerárquicas normativas nacionales, postura esta última de corte típicamente dualista. En otros términos, se trata de dar respuestas a los siguientes interrogantes: ¿Hasta dónde llegan las obligaciones asumidas por los Estados Partes en el sistema jurídico de MERCOSUR? En el caso de incumplimientos estatales por la no incorporación o por la no incorporación en debida forma de las normas comunes del derecho de integración derivado del bloque regional: ¿Las consecuencias jurídicas se limitan a la activación del procedimiento de Solución de Controversias de carácter interestatal previsto y a la eventual responsabilidad internacional de los Estados Partes por incumplimiento de un tratado o, yendo más allá, la naturaleza específica del tratado de integración permite la implementación de un sistema tutelar similar al de las directivas del derecho de integración de la Unión Europea en orden a resguardar el carácter vinculante, el efecto útil y la aplicación efectiva de la normativa común?5.

En este contexto, efectuando un análisis comparado de la naturaleza y de las características de cada uno de los procesos de integración y de sus respectivos sistemas jurídicos, Unión Europea y MERCOSUR, incluido lo vinculado a sus relaciones con los derechos nacionales de los Estados que los conforman y destacando semejanzas y diferencias, el trabajo presenta su planteamiento principal: pese a las asimetrías existentes entre ambos procesos de integración, ante incumplimientos de los Estados Partes del MERCOSUR de sus obligaciones de incorporar las normas comunes del derecho de integración derivado a sus derechos internos y de adaptar estos últimos en función de aquellas, resulta factible la recurrencia a soluciones desarrolladas en el ámbito de la Unión Europea con la finalidad de resguardar la eficacia jurídica de la normativa común y de permitir su aplicación efectiva, tutelando con

5 Cabe señalar que el problema jurídico planteado no dista mucho del existente en el ámbito de la Unión Europea al momento de consagrarse la doctrina del eficacia jurídica del derecho de integración originario primero y del derecho de integración derivado con posterioridad -particularmente de las directivas dada su necesidad de incorporación-, incluyendo lo vinculado a la aplicación preferente del derecho común respecto a los derechos nacionales, donde se dio preferencia al cumplimiento del derecho común pese a la oposición inicial de los Estados miembros, a través de la construcción de los principios de primacía y efecto directo; el otros términos, se optó por priorizar la voluntad objetivada de las partes en los tratados constitutivos en orden a permitir del cumplimiento de los objetivos allí trazados de común acuerdo, frente a voluntades e intereses estatales unilaterales contrarios. Al respecto puede verse: ALONSO GARCÍA, Ricardo. Sistema Jurídico de la Unión Europea. Cizur Menor, España: Editorial Civitas, 2014, p. 277. Resulta pertinente señalar en este punto que los tribunales arbitrales del MERCOSUR han consagrado una aplicación preferente parcial y limitada de la normativa común, puesto que la misma se reduce a la normativa vigente, y se la hace depender de lo dispuesto por los derechos nacionales respecto a la jerarquías normativas internas; al respecto pueden verse: Opinión Consultiva 01/2007, del 04 de marzo de 2007; Opinión Consultiva 01/2008, del 24 de abril de 2009; y Opinión Consultiva 01/2009, del 15 de junio de 2009. 
ello a los particulares y garantizando, en la medida de lo posible, sus derechos en tanto sujetos de la integración regional. Como se afirmó, dentro del derecho de integración de la Unión Europea en general, la investigación presta especial atención a las directivas como fuente del derecho de integración derivado, puesto que su particular mecanismo de actuación prevé un rol protagónico de los Estados miembros en orden a la aplicación de la normativa común, lo que aproxima a esta fuente normativa al derecho de integración derivado del MERCOSUR; a lo expresado se añade que es en el campo o en el terreno de las directivas donde la necesidad de resguardar su eficacia jurídica adquirió mayor desarrollo en virtud de su particular naturaleza y mecanismo de actuación.

En concreto, ante incumplimientos de los Estados miembros de la Unión Europea de incorporar las directivas a sus derechos nacionales y de adaptar los mismos al contenido material de aquellas, el Tribunal de Justicia de la Unión Europea desarrolló lo que en el contexto del presente trabajo se denomina doctrina de la eficacia jurídica de las directivas, doctrina jurisprudencial plasmada en una serie de manifestaciones que permiten la invocación de la normativa común por parte de los particulares ante las autoridades nacionales con distintos fines y efectos - procedentes tanto en supuestos de correcta actuación estatal como de incorrecta actuación estatal, pero que adquieren particular relevancia frente a incumplimientos estatales-, en orden a preservar los derechos que para ellos surgen de esta fuente del derecho de integración derivado, y no dejando librado al arbitrio de los Estados miembros su aplicación efectiva, lo que pone de manifiesto el doble matiz aplicativo-tutelar y sancionador de la doctrina.

Este resguardo del efecto útil del derecho de integración en general, y de las directivas en particular, fundamentado en su carácter normativo y obligatorio, se traduce en las siguientes manifestaciones de la eficacia jurídica de las mismas: su actuación como normas marco o normas base, la procedencia del recurso por incumplimiento ante supuestos de infracción, el reconocimiento de su efecto directo también ante supuestos de incumplimiento, la interpretación conforme de las disposiciones de los derechos nacionales en función de ellas, y la responsabilidad de los Estados miembros por daños y perjuicios causados a los particulares por infracción de lo dispuesto por ellas ${ }^{6}$.

Cabe destacar que desde la posición aquí sostenida y como se adelantó, la factibilidad de la aplicación de soluciones o respuestas jurídicas similares encuentra fundamento en la propia naturaleza del derecho de integración en tanto denominador común para ambos

$6 \mathrm{Al}$ respecto puede verse: PAVÓN PISCITELLO, D. Eficacia jurídica de las directivas en el derecho interno de los Estados miembros. Madrid: Ed. Centro de Documentación de la Unión Europea-UNED, 2004. 
procesos, y en las características presentes en cada uno de sus sistemas jurídicos. En otros términos, así como sobre la base de los tratados constitutivos de la actual Unión Europea su Tribunal de Justicia desarrolló y justificó las aludidas manifestaciones a partir del propio derecho de integración, no haciendo eje en lo dispuesto por cada uno de los ordenamientos jurídicos de los Estados miembros, la posición aquí sostenida encuentra apoyo y fundamentación jurídica en el propio derecho de integración del MERCOSUR y en las posibilidades que éste ofrece a partir de una interpretación finalista o teleológica, sistemática $\mathrm{y}$ funcional del mismo.

\section{EFICACIA JURÍDICA DE LA NORMATIVA COMÚN EN EL DERECHO DE INTEGRACIÓN DE MERCOSUR, MANIFESTACIONES POSIBLES}

Tomando fundamentos jurídicos de la doctrina desarrollada por el Tribunal de Justicia de la Unión Europea en orden a dotar de la máxima eficacia a las normas comunes, y profundizando en lo vinculado a las directivas por su mayor proximidad al derecho de integración derivado del MERCOSUR atento a su naturaleza y principalmente a su mecanismo de actuación en lo vinculado al rol protagónico asignado a los Estados en orden a la concreción de la normativa común, se entiende factible desde la posición aquí sostenida la aplicación de aspectos centrales de la aludida doctrina en el ámbito del proceso de integración del MERCOSUR, a partir de la naturaleza y caracteres específicos de este último. Siendo ello así, es el mismo derecho de integración del MERCOSUR el que posee las bases para mejorar la eficacia de sus normas comunes obligatorias reduciendo la dependencia de los Estados Partes, dependencia más próxima a esquemas de cooperación de derecho internacional clásico que a esquemas de integración en los cuales los particulares adquieren un rol protagónico como destinatarios de la normativa común y de derechos concretos de ella surgidos.

Como también se adelantó, la recurrencia al derecho de integración de la Unión Europea se justifica al tomar como referencia desarrollos originados en este sistema de integración a partir de elementos comunes presentes en el sistema de integración del MERCOSUR, consistentes esencialmente en la particular naturaleza de los procesos de integración, en la existencia de voluntades independientes y propias de las organizaciones-personas internacionales conformadas respecto a los Estados integrados, en el ejercicio conjunto de competencias en el seno de instituciones u órganos comunes con potestades normativas, en la autonomía de los ordenamientos jurídicos de integración creados - pese al carácter intergubernamental del proceso de integración del MERCOSUR-, en el carácter obligatorio de las normas comunes 
originarias y derivadas que componen los mismos, y en el aludido rol de los particulares como sujetos del derecho común -en tanto procesos de integración de Estados y de pueblos-.

Recurrencia al derecho de integración de la Unión Europea también justificada por la siguiente base de apoyo y fundamentación antes esbozada: así como la Unión Europea desarrolló y justificó la doctrina jurisprudencial vinculada a la eficacia jurídica de su derecho de integración a partir de la naturaleza del mismo y de lo dispuesto por sus tratados constitutivos, no haciendo eje en lo dispuesto por cada uno de los ordenamientos jurídicos de los Estados miembros, se entiende que en el ámbito del MERCOSUR resulta factible también desarrollar y justificar una doctrina vinculada a la eficacia jurídica de su derecho de integración a partir de su naturaleza y de su texto normativo, a partir de una interpretación teleológica o finalista, sistemática, funcional y evolutiva ${ }^{7}$ similar a la utilizada en su momento por el Tribunal de Justicia de la Unión Europea, que permita escapar a miradas restrictivas de los textos normativos, y evitando hacer eje en lo dispuesto por cada uno de los ordenamientos jurídicos de los Estados Partes.

Expresado lo anterior, la posición aquí defendida sostiene que la escasa aplicación efectiva del derecho de integración del MERCOSUR en general, y de su derecho derivado en particular, derecho de carácter obligatorio para los Estados Partes, puede revertirse a partir de la instrumentación de diversas manifestaciones de la eficacia jurídica de las normas comunes en procesos de integración, manifestaciones traducidas en respuestas o soluciones jurídicas prácticas, las que en el ámbito del MERCOSUR adquieren rasgos diferenciales y diverso contenido y alcance que en el ámbito de la Unión Europea, esto en función de los diversidades existentes entre ambos sistemas de integración.

En este marco y yendo de lo general a lo particular, se entiende que el sistema de vigencia simultánea contemplado por el derecho de integración del MERCOSUR no implica necesariamente sujetar la aplicación efectiva de las normas comunes de su derecho derivado -Decisiones, Resoluciones y Directivas- a las voluntades unilaterales y coyunturales de los Estados Partes de incorporarlas o no, puesto que el carácter obligatorio de las mismas, sumado a su adopción en el marco de los órganos comunes del esquema de integración actuando en ejercicio de competencias atribuidas al efecto por los Estados Partes, permite la aplicación de las aludidas soluciones o respuestas jurídicas. Desde la tesis o postura aquí sostenida, al estar los Estados Partes del MERCOSUR obligados a incorporar las normas comunes, y a partir de

7 La necesaria interpretación evolutiva del derecho de integración del MERCOSUR en función del objeto y fin del proceso de integración fue reconocida y destacada por los tribunales arbitrales del MERCOSUR en diversos pronunciamientos, entre otros: Laudo I, del 28 de abril de 1999 y Laudo III, del 10 de marzo de 2000. 
ello alcanzar lo establecido por su contenido material, ante supuestos de incumplimiento estatal, las normas comunes son susceptibles de ser invocadas por los particulares con distintos fines y efectos, debiendo ser tomadas en consideración por los jueces o tribunales y demás autoridades nacionales.

Lo expresado precedentemente implica afirmar que los Estados Partes no están facultados a bloquear, ni para sí mismos dentro de sus jurisdicciones, ni para los demás Estados Partes, la aplicación del derecho derivado común, no pudiendo privarlo de su eficacia. Implica, asimismo, afirmar que los particulares, en tanto sujetos protagónicos del proceso de integración del MERCOSUR ${ }^{8}$, están llamados, como se adelantó, a obtener una garantía mínima de tutela de sus derechos frente a incumplimientos estatales que puede ser reclamada antes sus autoridades nacionales y debe ser garantizada por ellas, hasta tanto los Estados Partes adecuen sus conductas al derecho común. La postura sostenida importa pasar de una situación que fue sintetizada al inicio de este trabajo en la relación obligatoriedad - incumplimiento - no vigencia de la normativa común, a una situación que puede ser sintetizada en la relación obligatoriedad - incumplimiento - vigencia de la normativa común, aunque se trate de una vigencia limitada en virtud de los diversos alcances y efectos de cada una de las manifestaciones, respuestas o soluciones jurídicas, y hasta tanto se concrete la mencionada adecuación

8 Respecto a lo expresado ut supra y desde la posición aquí sostenida, el proceso de integración del MERCOSUR es poseedor de un doble carácter o de una doble legitimidad, constituyendo una unión de pueblos y una unión de Estados a la vez -aunque con diversa intensidad o magnitud a lo que ocurre en la Unión Europea donde el reconocimiento del rol de los particulares como sujetos de la integración resulta mayor-. Este doble carácter, reconocido por la jurisprudencia de los tribunales arbitrales del MERCOSUR, posee diversas manifestaciones: la necesidad de ratificación del tratado constitutivo, sus protocolos e instrumentos adicionales o complementarios por parte de los Poderes Legislativos de los Estados Partes; la inclusión dentro de la estructura institucional de los particulares o ciudadanos en tanto pueblos mediante su participación en la conformación del Parlamento del MERCOSUR y del Foro Consultivo Económico-Social, órganos que actúan en conjunto con órganos representativos de los intereses de los Estados Partes y de los intereses generales del proceso de integración; todo ello sin olvidar lo dispuesto por el Preámbulo del MERCOSUR sobre los habitantes y los pueblos de los Estados Partes, ni el amplio desarrollo de la dimensión social del MERCOSUR o del denominado MERCOSUR social. Al respecto puede verse: FREELAND LÓPEZ LECUBE, A.; GATTINONI DE MUJIA, M.; PEROTTI, A. "El efecto directo de las normas MERCOSUR y el asunto Van Gend and Loos". Revista de Derecho Internacional y del MERCOSUR. 2002, p. 75; NASCIMENTO, M. A Incorporacão das Normas do MERCOSUR aos Ordenamentos Jurídicos dos Estados-membros. Curutiba: Juruá Editora, 2006, p. 17 y ss; SALOMÃO FILHO C.; SAMTLEBEN, J. "Der Südamerikanische Gemeinsame Markt - Eine rechtliche Analyse des MERCOSUR". En Wertpapiermitteilungen. Buenos Aires: s.n, 1992, p. 1346; SCHMIDT, J. "El estado actual del MERCOSUR y las perspectivas para su futuro desarrollo: problemas y oportunidades". En ¿Integración suramericana a través del derecho? Un análisis interdisciplinario y multifocal. Madrid: Centro de Estudios Políticos y Constitucionales Max Planck-Institüt, 2009, p. 524; RAMOS CUADRADO, D. "Protección Jurídica para los particulares en el Mercosur". En Contribuciones Konrad Adenauer. Montevideo: CIEDLA, 1999. En materia de jurisprudencia de los tribunales arbitrales del MERCOSUR, entre otros pronunciamientos, puede verse: Laudo I, del 28 de abril de 1999; Laudo III, del 10 de marzo de 2000; y Laudo XII, del 06 de septiembre de 2006. 
a derecho por los Estados Partes.

La fundamentación jurídica de la aplicación de la doctrina de la eficacia jurídica al derecho de integración derivado del MERCOSUR frente a conductas de incumplimiento estatal se estructura, desde la postura aquí sostenida, en torno a un tronco común determinado por su naturaleza normativa, y a partir de allí resulta posible identificar una serie de fundamentos específicos vinculados, entre los que se destacan: el carácter obligatorio o vinculante de sus normas comunes del MERCOSUR para los Estados Partes destinatarios, expresamente consagrado en los artículos 9, 15, 20 y 42 POP (Protocolo del Ouro Preto); el consecuente deber de cooperación leal o lealtad de los Estados Partes para con el proceso de integración, consagrado también de manera expresa en el artículo 38 POP y traducido en la exigencia de adoptar todas las medidas pertinentes y necesarias para asegurar el cumplimiento de sus obligaciones y de las normas comunes adoptadas; la necesidad de resguardar el efecto útil de las normas comunes y de otorgar una tutela directa a los particulares en tanto destinatarios y beneficiarios de ellas, garantizando su aplicación, aunque sea mínima, en el ámbito de sus esferas jurídicas concretas -efecto útil que resultaría debilitado si los particulares no pudieran invocar las aludidas normas comunes ante los Estados Partes incumplidores, particularmente antelos órganos jurisdiccionales nacionales en cuanto garantes del derecho de integración; la importancia de implementar mecanismos sancionadores o punitivos frente a incumplimientos de los Estados Partes, mecanismos de presión basados tanto en la aplicación de la normativa común por parte de las autoridades nacionales en cada una de las jurisdicciones estatales, como en la actuación protagónica de los particulares como promotores o impulsores del derecho de integración, y que implican la aceptación por parte de los Estados de las consecuencias jurídicas de la invocabilidad en su contra de las disposiciones de las normas comunes. Interesa resaltar que los argumentos jurídicos esgrimidos para la aplicación de la doctrina de la eficacia jurídica al derecho de integración del MERCOSUR resultan muy próximos a los invocados para la consagración de esta doctrina en el ámbito del derecho de integración de la Unión Europea ${ }^{9}$.

9 Los argumentos jurídicos que fundamentan la doctrina de la eficacia jurídica en el ámbito del derecho de integración de la Unión Europea, particularmente de las directivas, pueden resumirse en los siguientes: el carácter obligatorio de estas normas para los Estados miembros destinatarios, consagrado en el artículo 288 TFUE (Tratado de Funcionamiento de la Unión Europea) y consecuencia directa e inmediata de su naturaleza normativa; el vinculado deber y principio de cooperación leal o de lealtad para con el proceso de integración consagrado en el artículo 4 TUE (Tratado de la Unión Europea), por el cual los Estados miembros quedan obligados a la adopción de todas las medidas generales o particulares pertinentes en orden a asegurar el cumplimiento de sus obligaciones; la aludida necesidad de resguardar el efecto útil de las normas comunes; la instrumentación de una tutela directa del derecho de integración sobre las esferas jurídicas concretas de los particulares en tanto destinatarios del 
Expuesto todo lo anterior y partir de un análisis del proceso de integración del MERCOSUR, comprensivo del estudio integral de su ordenamiento jurídico y de la jurisprudencia de los órganos comunes de administración de justicia -Tribunales Arbitrales ad hoc y Tribunal Permanente de Revisión-, y de un estudio también integral del ordenamiento jurídico y de la jurisprudencia de los órganos comunes de administración de justicia del proceso de integración de la Unión Europea como marco de referencia atento a los desarrollos allí alcanzados, siempre reconociendo similitudes y diferencias entre ambos esquemas de integración ${ }^{10}$, resulta posible afirmar que existen diversas manifestaciones concretas de la eficacia jurídica de la normativa común que debieran ponerse en valor, ya sea con el objeto de potenciar su aplicación en el caso de aquellas que se encuentran operativas, ya sea con el objeto de implementar las mismas en el caso de aquellas que no han sido reconocidas formalmente ${ }^{11}$. Las aludidas manifestaciones de la eficacia jurídica de la normativa común, propuestas de solución concretas destinadas a mejorar la aplicación efectiva del derecho de integración del MERCOSUR y con ello propiciar el avance del proceso de integración, son susceptibles de resumirse en las siguientes:

\subsection{La actuación de las normas comunes del derecho de integración derivado del MERCOSUR como normas marco o normas base respecto a las normas o medidas nacionales vinculadas a su concreción de los Estados Partes}

Desde la posición aquí sostenida esto constituye una manifestación natural y primigenia de las normas comunes, manifestación que se traduce en la actuación de las normas comunes como parámetros de referencia para la actuación de los Estados Partes en orden a su ejecución, comprensiva tanto de la incorporación de las mismas como

ordenamiento jurídico común; y la implementación de mecanismos sancionadores frente a incumplimientos estatales, que incluyen la invocabilidad en su contra del contenido material de las normas comunes.

10 Atento a lo expresado, cabe resaltar una vez más que la recurrencia a la aplicación de la doctrina del eficacia jurídica del derecho de integración de la Unión Europea, principalmente de las directivas, al ámbito del derecho de integración derivado del MERCOSUR no consiste en una mera transposición o transferencia de la aludida doctrina, sino en una adaptación de sus manifestaciones a partir de situaciones fácticas y jurídicas próximas ante supuestos de incumplimiento estatal, de allí que difiera su alcance y contenido y se establezcan semejanzas y diferencias con lo que ocurre en el ámbito de la Unión Europea.

11 El aludido análisis abarca al estudio de las naturalezas de cada uno de los procesos de integración, las características generales de sus derechos comunes y de sus principios rectores de sus relaciones con los derechos nacionales, siempre contemplando semejanzas y diferencias fácticas y jurídicas, para luego concretar en alcance de la doctrina de la eficacia jurídica en el ámbito del MERCOSUR, en función de las posibilidades del sistema jurídico-institucional actual. Una profundización de este análisis podrá verse en: PAVÓN PISCITELLO, D. Eficacia jurídica de la normativa común en procesos de integración regional [en prensa]. Córdoba, Argentina: Ed. Universidad Católica de Córdoba, 2017. 
de la correcta adaptación de los derechos internos en orden a posibilitar la concreción de su contenido material en sus respectivas jurisdicciones en los plazos establecidos; la manifestación resulta operativa tanto en supuestos en los que aún no se haya producido la actuación estatal como en supuestos en los que ella se haya producido, en estos últimos a fin de validar la adecuación o corrección de la aludida actuación -incorporación y adaptación en debida forma- ${ }^{12}$.

Por esta manifestación de la eficacia jurídica de las normas comunes quedan obligados todos los poderes y autoridades de los Estados Partes en el ejercicio de sus funciones. Se trata de una manifestación actualmente presente en el ámbito del MERCOSUR, cuyos efectos y aplicación se entiende conveniente potenciar.

\subsection{La recurrencia al Sistema de Solución de Controversias del MERCOSUR por incumplimiento de las normas comunes de su derecho de integración derivado}

Desde la posición aquí sostenida esto constituye una manifestación clásica de la eficacia jurídica de las normas comunes frente a situaciones de eventual infracción, asociada a su carácter obligatorio. Esta manifestación se traduce en la posibilidad de la implementación del sistema frente a supuestos de incumplimiento de los Estados Partes de las obligaciones a su cargo respecto de las normas del derecho de integración derivado -incorporación y adaptación-, en orden a la determinación y eventual declaración de su responsabilidad por parte de los tribunales arbitrales del MERCOSUR, y a la implementación de medidas compensatorias temporales tendentes a lograr la pertinente adecuación a derecho en supuestos de laudos arbitrales condenatorios, adecuación ex post que de producirse posee efectos erga omnes a futuro.

Siempre desde la posición aquí sostenida, la manifestación resultaría operativa tanto en supuestos en los que los Estados Partes no hayan actuado dentro de los plazos establecidos, como en supuestos en los que sí lo hayan hecho pero de manera incorrecta o incompleta de modo que la adaptación de los derechos internos no garantice el contenido material de las normas comunes -dado el particular procedimiento de vigencia de las normas comunes del derecho de integración derivado del MERCOSUR quedarían incluidas situaciones de falta de vigencia simultánea, normas comunes incorporadas en uno o más Estados Partes pero sin vigencia común por falta de incorporación en todos ellos-, todo ello sin excluir supuestos de incorporación y de adecuada adaptación,

12 La utilidad práctica de esta manifestación en el ámbito del MERCOSUR resulta menor que en el ámbito de la Unión Europea para las directivas, atento a la obligación de incorporación integral -textual- de su derecho de integración derivado, aplicable a partir del año 2003 (Decisión CMC 20/02). 
pero de falta de cumplimiento efectivo del contenido material de las normas de origen común.

Los legitimados activos de esta manifestación son los Estados Partes a partir de lo establecido por el sistema actual, pudiendo los particulares afectados solamente impulsar el procedimiento ante los órganos comunes (Grupo Mercado Común), no garantizando la manifestación aquí aludida la aplicación del derecho común a las relaciones jurídicas concretas en cuestión -puesto que se debe esperar a la mencionada adecuación a derecho-, aspectos que muestran el carácter limitado de la misma ${ }^{13}$. Se trata también de una manifestación actualmente presente en el ámbito del MERCOSUR, cuyos efectos y aplicación se entiende conveniente potenciar.

\subsection{El reconocimiento del efecto directo de las normas comunes del derecho de integración derivado del MERCOSUR ante supuestos de incumplimiento estatal de las mismas}

Desde la posición o tesis aquí sostenida esta manifestación se traduciría en la posibilidad de la invocación de este efecto de las normas comunes por parte de los particulares frente a los Estados Partes incumplidores en orden al reconocimiento de los derechos a ellos atribuidos, de manera directa y en sus relaciones jurídicas concretas ${ }^{14}$.

Siempre desde la posición defendida, la manifestación resultaría operativa tanto en supuestos en los que los Estados Partes no hayan actuado dentro de los plazos establecidos y procedido a la incorporación de las normas comunes y a la adaptación a ellas de sus respectivos derechos internos, como en supuestos en los que sí lo hayan hecho pero de manera incorrecta o incompleta no conforme a su contenido material.

Los legitimados activos de esta manifestación serían los particulares afectados, aunque su aplicabilidad quedaría sujeta a requisitos restrictivos ligados al contenido de las normas comunes en cuestión -precisión e incondicionalidad-, y al carácter de los sujetos vinculados, siendo procedente únicamente el efecto directo invocado por los particulares frente a los Estados Partes -no el invocado en contra

\footnotetext{
13 La utilidad práctica de esta manifestación -próxima al recurso por incumplimiento del derecho de integración de la Unión Europea-, resulta menor en el ámbito del MERCOSUR que en el ámbito europeo para las directivas, atento a la menor eficacia del sistema de sanción -medidas compensatorias no previamente determinadas en una segunda instancia condenatoria, frente a la aplicación de sumas a tanto alzado y multas coercitivas operativas desde un primer momento-.

14 Lo señalado implica defender la integración inmediata de la normativa común a los ordenamientos jurídicos nacionales, para lo cual existe una sólida base argumentativa derivada del propio ordenamiento jurídico del MERCOSUR, y donde debates acaecidos en el ámbito de la Unión Europea en su momento también brindan importantes orientaciones. Al respecto puede verse: PAULO PEREIRA, A. Direito Institucional e Material do MERCOSUL. Rio de Janeiro: Editora Lumen Juris, 2005, p. 75 y ss.
} 
de los particulares, lo que importa la negación de efecto vertical inverso y del efecto horizontal, atento a que los particulares no deberían verse perjudicados por incumplimientos estatales que les son ajenos-.

Como fue objeto de aclaración precedente, en supuestos de normas comunes incorporadas por algunos Estados Partes pero sin vigencia simultánea por la falta de incorporación en todos los Estados Partes en virtud del sistema adoptado por el MERCOSUR, la manifestación aquí tratada implicaría que la aplicación de las normas comunes sería plena para los Estados Partes cumplidores luego del vencimiento de los plazos establecidos al efecto, no quedando condicionada o sujeta en este caso la aludida aplicación normativa a la incorporación de los Estados Partes incumplidores, esto en resguardo de la eficacia jurídica de las normas comunes y a fin de impedir que un sólo Estado Parte pueda bloquear el sistema; lo expresado permitiría o haría posible la aplicación normativa frente a supuestos de incumplimiento estatal, e impediría que un solo Estado Parte pueda bloquear el sistema con consecuencias para el conjunto.

Si bien la consagración del efecto directo implicaría un resguardo mínimo aplicable en Estados Partes incumplidores -y una situación diversa respecto a lo que ocurre en los Estados Partes cumplidores-, el alcance de la manifestación en el ámbito del MERCOSUR resultaría similar a lo que ocurre en el ámbito de la Unión Europea para las directivas -lo que incluye el efecto bloqueo desde la adopción de las mismas y aun cuando no hayan expirado los plazos establecidos para la incorporación y adecuación normativa-. Se trata también de una manifestación actualmente no reconocida el ámbito del MERCOSUR, cuyos efectos y aplicación se entiende conveniente instrumentar.

\subsection{La interpretación conforme de los derechos nacionales en función de las normas comunes del derecho de integración derivado del MERCOSUR}

Desde la posición aquí sostenida, esta manifestación resulta operativa tanto en supuestos de adecuado cumplimiento estatal de las obligaciones surgidas de las normas comunes del derecho de integración derivado como en supuestos de incumplimiento estatal -incluyendo por tanto normas comunes incorporadas y vigentes de manera simultánea, como normas comunes incorporadas pero sin vigencia simultánea por falta de incorporación a todos los Estados Partes, y normas comunes aun no incorporadas, ya sea en casos de adaptación estatal correcta desde el punto de vista material o no- ${ }^{15}$.

15 La manifestación poseería un alcance similar al que posee en el ámbito de la Unión Europea, lo que incluye el efecto anticipación desde la adopción de las mismas y mientras no se hayan cumplido los plazos establecidos para la incorporación y adecuación normativa. No obstante lo expresado, la utilidad práctica de esta manifestación resultaría menor en el ámbito del MERCOSUR en comparación con lo que ocurre en el ámbito de la Unión Europea, 
Por esta manifestación de la eficacia jurídica de las normas comunes y con la amplitud señalada quedarían obligadas las autoridades nacionales, especialmente los jueces o tribunales en tanto garantes del derecho común, gozando los particulares de legitimación para invocar la misma. La manifestación poseería los límites derivados de la labor hermenéutica o interpretativa, lo que muestra el alcance limitado de la misma. Se trata también de una manifestación actualmente presente en el ámbito del MERCOSUR, pero con alcance limitado a parcial ${ }^{16}$, cuyos efectos y aplicación se entiende conveniente potenciar.

\subsection{La responsabilidad de los Estados Partes por daños y perjuicios causados a los particulares por infracción de las normas comunes del derecho de integración derivado del MERCOSUR}

La manifestación resultaría operativa, desde la posición aquí sostenida, en supuestos en los que frente a incumplimientos o infracciones estatales de las aludidas normas comunes -normas comunes no incorporadas o no adaptadas correctamente desde el punto de vista material, aunque no en supuestos de falta de vigencia por causas ajenas a los Estados Partes en cuestión e imputables a otros Estados Partes-, no se haya podido impedir daños a los particulares que hubiesen adecuado sus conductas de conformidad a las mismas, ni por vía interpretativa ni por vía del reconocimiento del efecto directo de estas normas comunes.

Por esta manifestación de la eficacia jurídica de las normas comunes quedarían obligadas las autoridades nacionales, especialmente los jueces o tribunales por su específica función, gozando los particulares de legitimación activa para invocar las actuaciones tendentes al reconocimiento de la aludida responsabilidad. La manifestación poseería límites específicos derivados de la entidad de las infracciones, lo que también pone de manifiesto el alcance de la misma ${ }^{17}$. Se trata de otra

atento a que la ya mencionada obligación de incorporación integral -textual- provoca que la materia a interpretar sea más reducida. Lo vinculado a los efectos bloqueo y anticipación, según de trate de la eficacia aplicativa o interpretativa de las normas comunes, puede verse en: BELLIDO BARRIONUEVO, M. "La eficacia interpretativa de la directiva comunitaria durante el período de transposición: el efecto anticipación de la directiva en conexión con el efecto bloqueo". Cuadernos de Derecho Público, 2005, n² 24, p. 159 y sig.

16 Los tribunales arbitrales del MERCOSUR han tenido oportunidad de pronunciarse sobre la importancia de interpretar tanto el propio derecho de integración como las normas internas de los Estados Partes vinculadas en orden a lograr una interpretación común en los Estados Partes, ello en función de lo prescripto por artículo 38 POP. No obstante ello, parecieran reducir lo expresado al derecho de integración que adquiera vigencia simultánea, lo que para el derecho de integración derivado del MERCOSUR resulta muy restrictivo, puesto que se vuelve a hacer depender la eficacia jurídica del derecho común, en este caso en su faceta interpretativa, de las voluntades unilaterales de los Estados Partes. Al respecto puede verse: Opinión Consultiva 01/2007, del 04 de marzo de 2007.

17 Desde la postura aquí sostenida, el alcance de esta manifestación resultaría similar al que posee en el ámbito de la Unión Europea para las directivas, por lo que se aplicaría a 
manifestación actualmente no reconocida el ámbito del MERCOSUR, cuyos efectos y aplicación se entiende conveniente instrumentar.

En función de todo lo expuesto, se entiende que los fundamentos jurídicos básicos sobre los que oportunamente se construyó la doctrina de la eficacia jurídica de las normas comunes en el ámbito del derecho de integración de la Unión Europea, esto es el carácter normativo y obligatorio de estas normas para los Estados integrados y el resguardo del efecto útil de las mismas en el marco de un ordenamiento jurídico destinado no solamente a los Estados sino también a los particulares, resultan también aplicables al derecho de integración del MERCOSUR, todo esto pese a la ausencia de supranacionalidad del mismo. Respecto a esto último, resulta también ilustrativa y aleccionadora la postura y la jurisprudencia del Tribunal de Justicia de la Unión Europea respecto al derecho derivado surgido de los órganos comunes previstos en los tratados internacionales de asociación y de cooperación celebrados entre la Unión Europea y terceros Estados, ámbitos donde lo que impera es la intergubernamentalidad ${ }^{18}$.

La recurrencia a los aludidos fundamentos jurídicos y las manifestaciones de la eficacia jurídica a partir de los mismos y con el alcance indicado llevarían entonces a favorecer la aplicación del derecho común en el espacio integrado del MERCOSUR reduciendo la dependencia de los Estados Partes, dependencia más próxima a esquemas de derecho internacional clásico que a esquemas de derecho

infracciones de cierta entidad, graves y manifiestas -violaciones suficientemente caracterizas en el lenguaje jurídico de la Unión Europea-. Al respecto puede verse: ALONSO GARCÍA, R. La responsabilidad de los Estados miembros por infracción del Derecho Comunitario. madrid: Ed. Civitas, 1989.

18 El aludido carácter intergubernamental del proceso de integración del MERCOSUR no constituye desde la posición aquí sostenida un obstáculo para el reconocimiento del efecto directo y la aplicación preferente de su normativa común, puesto que se entiende que del ejercicio conjunto de competencias por los Estados Partes, en el marco de los órganos del MERCOSUR, surge una voluntad diversa y autónoma del proceso de integración por la que la organización internacional se encuentra facultada para dictar normas obligatorias para los Estados Partes. Frente a esto, un eventual derecho de veto de los Estados Partes podría manifestarse mediante su negativa a adoptar las normas comunes por el sistema de consenso, pero no luego de ello, puesto que a través de la adopción normativa confirman su voluntad de obligarse por las normas comunes, de carácter vinculante de conformidad al propio texto normativo del MERCOSUR. En lo referente a la jurisprudencia europea en el marco de acuerdos o tratados internacionales de asociación y/o de cooperación entre la Unión Europea y terceros Estados, el Tribunal de Justicia de la Unión Europea consagró en jurisprudencia constante que en estos esquemas de carácter intergubernamental las partes contratantes pierden la facultad de adoptar medidas que obstaculicen ulteriormente el ejercicio de derechos surgidos de normas comunes de derecho derivado adoptadas por los órganos creados; al respecto pueden verse, entre muchos otros pronunciamientos: sentencia Sevince, de 20 de septiembre de 1990, as. C-192/89; sentencia Sürül, de 4 de mayo de 1999, as. C-262/96; sentencia República Portuguesa contra Consejo de la Unión Europea, de 23 de noviembre de 1999, as. C-149/96; sentencia Nazli, de 10 de febrero de 2000, as. C-340/97; sentencia Safet Eyüp c. Landesgeschäftsstelle des Arbeitmarktservice Vorarlberg, de 22 de junio de 2000, as. C-65/98; y sentencia Mohamed Gattoussi contra Stadt Rüsselsheim, de 14 de diciembre de 2006, as. C-97/05. 
de integración donde los particulares adquieren un rol protagónico como destinatarios de la normativa común. En concreto, desde la posición sostenida, ni el carácter intergubernamental del MERCOSUR ni el sistema de vigencia simultánea contemplado por su derecho de integración para su derecho derivado implican sujetar la aplicación efectiva de las normas comunes a las voluntades unilaterales y coyunturales de los Estados Partes de incorporarlas o no, puesto que al estar los Estados Partes obligados a incorporar las normas comunes, y a partir de ello alcanzar lo establecido por su contenido material, ante incumplimientos estatales las normas comunes son suceptibles de ser invocadas por los particulares ante sus autoridades nacionales con distintos fines y efectos como se ha visto. En otros términos, lo señalado implica afirmar que los Estados Partes no están facultados a bloquear, ni para sí mismos dentro de sus jurisdicciones, ni para los demás Estados Partes, la aplicación del derecho de integración derivado atento al carácter obligatorio del mismo.

\section{CONCLUSIÓN}

Se entiende que el artículo sienta las bases para reflexionar sobre la eficacia jurídica de la normativa común en procesos de integración regional en general, y deja planteada concretamente la factibilidad jurídica y la utilidad práctica de la aplicación de manifestaciones de la doctrina de la eficacia jurídica del derecho de integración de la Unión Europea, particularmente de las directivas, al derecho de integración del MERCOSUR, con énfasis en su derecho derivado y en orden a su concreción. La tesis defendida sostiene que la aplicación de las aludidas manifestaciones permite complementar mecanismos interestatales clásicos de responsabilidad internacional de los Estados ante incumplimientos de la normativa común en el marco de procesos de integración, en orden a favorecer tanto la aplicación efectiva de la normativa común, como la adecuación a derecho de los comportamientos estatales, lo que supone un resguardo o una garantía para los particulares y a la vez supone su actuación protagónica en el ámbito de sus respectivas jurisdicciones nacionales y ante sus autoridades como promotores del derecho común.

La tesis o posición aquí defendida implica afirmar si bien en el ámbito del MERCOSUR no es posible sostener la existencia de una vocación natural o primigenia del derecho de integración derivado para regir situaciones concretas y llegar por sí mismo y directamente a regular las relaciones jurídicas de los particulares sujetos a las diferentes jurisdicciones estatales -al igual que ocurre con las directivas en el ámbito del derecho de integración de la Unión Europea, aunque no necesariamente por los mismos motivos, y lo que importa respetar el 
sistema jurídico actual del MERCOSUR-, lo expresado es o debería ser cierto solamente en una primera etapa de la existencia de las normas comunes; en una segunda etapa de su existencia, su propia naturaleza jurídica les reclama operatividad y aplicabilidad para la regulación de situaciones concretas en virtud de su efecto útil y en orden a garantizar, en la medida de lo posible y en función del contenido material de las mismas, el principio de tutela judicial efectiva, lo que resulta posible a través de diversas manifestaciones de su eficacia jurídica, las que han sido brevemente expuestas.

Se entiende que la esencia misma del proceso de integración regional es la que reclama una interpretación finalista o teleológica del ordenamiento jurídico creado y exige la aplicación fáctica de las normas comunes, aplicación que no puede quedar supeditada a la voluntad unilateral de cada uno de los Estados Partes, atento al propio carácter obligatorio de las mismas. Siendo ello así, la sustancia de la integración está llamada a hacerse presente a través de las diversas manifestaciones de la eficacia jurídica de las normas comunes, señalando a los Estados Partes la actuación o el camino debido en el marco del proceso de integración al cual se han comprometido.

A partir de lo desarrollado, se considera que las bases jurídicas para reforzar la eficacia del derecho de integración del MERCOSUR existen y están dadas por el propio sistema normativo, y que las mismas han quedado expuestas. No obstante ello, lo que quedaría por definir es la voluntad política de los Estados Partes en orden a aceptar o no una interpretación del sistema jurídico del MERCOSUR como la expuesta. En caso de ser esta aceptada, desde lo jurídico se habría contribuido a terminar con la actual parálisis del proceso de integración regional; en caso contrario, sería aconsejable desde la posición aquí sostenida un cambio del sistema jurídico actual, a fin de evitar que las normas comunes queden en letra muerta y con ello languidezca el propio proceso de integración regional, todo ello en un subcontinente cansado de observar el surgimiento y el ocaso de espacios de integración que no cumplen las expectativas para los que fueron ideados, en buena medida por la preeminencia de factores políticos y de intereses estatales individuales por sobre el derecho común ${ }^{19}$.

Para finalizar, señalar que se entiende que el futuro del MERCOSUR dependerá de su contribución o eficacia para mejorar la situación en la que se encuentran sus Estados Partes y sus habitantes, contribución o eficacia que se encuentra vinculada a la aplicación efectiva del derecho común. Más allá de lo expresado, una eventual

19 Como se adelantó, se entiende que la tesis aquí sostenida contribuye a concretar o hacer efectiva la voluntad objetivada de los Estados Partes plasmada en el actual ordenamiento jurídico del MERCOSUR, ello frente a voluntades unilaterales de los Estados Partes, por lo general variables en función de intereses coyunturales de conveniencia política. 
apuesta por otros procesos de integración regional que reemplacen o absorban al MERCOSUR, no debería dejar de considerar lo señalado, puesto que la falta de aplicación y eficacia de la normativa común ha constituido y constituye un problema común en diversos procesos de integración latinoamericanos.

\section{RESUMEN BIOGRÁFICO}

Daniel Pavón Piscitello es Doctor en Derecho y Magister Iuris en Derecho de la Integración por la Universidad Complutense de Madrid, España. Profesor Titular de Derecho Internacional y Profesor Investigador en la Universidad Católica de Córdoba, Argentina. Profesor de Relaciones Internacionales en la Universidad Nacional Tres de Febrero, Argentina. Delegado Regional e Investigador en la Fundación CIDEAL de Cooperación e Investigación, España.

\section{REFERENCIAS BIBLIOGRÁFICAS}

ALONSO GARCÍA, R. La responsabilidad de los Estados miembros por infracción del Derecho Comunitario. madrid: Ed. Civitas, 1989.

ALONSO GARCÍA, Ricardo. Sistema Jurídico de la Unión Europea. Cizur Menor, España: Editorial Civitas, 2014

BELLIDO BARRIONUEVO, M. "La eficacia interpretativa de la directiva comunitaria durante el período de transposición: el efecto anticipación de la directiva en conexión con el efecto bloqueo". Cuadernos de Derecho Público, 2005, n² 24, p. 159-173.

FREELAND LÓPEZ LECUBE, A.; GATTINONI DE MUJIA, M.; PEROTTI, A. "El efecto directo de las normas MERCOSUR y el asunto Van Gend and Loos". Revista de Derecho Internacional y del MERCOSUR. 2002, p. 75

NASCIMENTO, M. A Incorporacão das Normas do MERCOSUR aos Ordenamentos Jurídicos dos Estados-membros. Curutiba: Juruá Editora, 2006, p. 17.

PAULO PEREIRA, A. Direito Institucional e Material do MERCOSUL. Rio de Janeiro: Editora Lumen Juris, 2005.

PAVÓN PISCITELLO, D. Eficacia jurídica de la normativa común en procesos de integración regional [en prensa]. Córdoba, Argentina: Ed. Universidad Católica de Córdoba, 2017.

PAVÓN PISCITELLO, D. Eficacia jurídica de las directivas en el derecho interno de los Estados miembros. Madrid: Ed. Centro de Documentación 
de la Unión Europea -UNED, 2004.

PAVÓN, D.; SCHMIDT, J. "In the footsteps of the ECJ: First decision of the Permanent MERCOSUR-Tribunal". Kluwer Law International. 2007, $\operatorname{vol} 34, \mathrm{n}^{\circ} 3$

RAMOS CUADRADO, D. "Protección Jurídica para los particulares en el Mercosur". En Contribuciones Konrad Adenauer. Montevideo: CIEDLA, 1999.

SALOMÃO FILHO C.; SAMTLEBEN, J. "Der Südamerikanische Gemeinsame Markt - Eine rechtliche Analyse des MERCOSUR". En Wertpapiermitteilungen. Buenos Aires: s.n, 1992.

SCHMIDT, J. "El estado actual del MERCOSUR y las perspectivas para su futuro desarrollo: problemas y oportunidades". En ¿Integración suramericana a través del derecho? Un análisis interdisciplinario y multifocal. Madrid: Centro de Estudios Políticos y Constitucionales Max Planck-Institüt, 2009. 